\title{
YIELD LINE THEORY AND CONCRETE PLASTICITY
}

\author{
Mikael W BRAESTRUP
}

Ramboll Oil \& Gas, Denmark

Keywords: Concrete structures, Mathematical modelling, Slabs \& plates.

\section{INTRODUCTION}

The mathematical theory of plasticity, or limit analysis, was developed around the middle of the $20^{\text {th }}$ century by Hodge, Drucker, Prager and Greenberg [1-4] in the USA and Hill [5] in the UK. Making use of extremum principles that can be traced back at least to Coulomb [6], the theory aims to predict the collapse load of a structure by means of the three limit analysis theorems: Upper Bound, Lower Bound and Uniqueness. The material properties are described by a yield condition, defining all stress states that can be sustained. The convex frontier of the allowable stress states is the yield surface, which is also the plastic potential for the strain increments that may occur for stress states on the yield surface. Limit analysis can be applied to any material or structure that can reasonably be described as rigid, perfectly plastic. Basically, this requires the absence of stability issues or large deformations, ensuring that elastic strains can be neglected, and adequate ductility, ensuring the necessary redistribution of stresses without excessive damage or rupture.

Yield line theory, on the other hand, is an efficient way of determining the collapse load of reinforced concrete slabs, and it pre-dates limit analysis. The term 'yield line' (in Danish: 'brudlinie', literally meaning 'line of rupture') was coined in 1921 by Ingerslev [7] to describe lines in the slab along which the bending moment is constant. In $1931 \mathrm{~K} \mathrm{~W}$ Johansen [8] gave the concept a geometrical meaning as lines of relative rotation of rigid slab parts, and in 1943 [9] published the eponymous theory. Yield line analysis was adopted by the Danish concrete code, and introduced into the curriculum at the Technical University of Denmark. There is anecdotic evidence to the effect that the success of Danish engineers worldwide in the decades immediately following the Second World War owed no small part to their mastery of yield line analysis, allowing them to produce efficient designs of reinforced concrete slabs of any shape and loading, while their foreign colleagues were struggling with tables of elastic moments and influence surfaces, leading to excessive amounts of reinforcement, and applicable to standard cases only.

\section{LIMIT ANALYSIS AND YIELD LINES}

The fathers of limit analysis immediately recognised yield line theory as an ingenious method of computing upper bound solutions for reinforced concrete slabs (Prager [4]) and in the early 1960s the mathematical theory of plasticity was seized by M P Nielsen, then a research student with Prof Johansen. In the resulting thesis Nielsen [10] derived the yield condition for orthogonally reinforced slabs (in a coordinate system oriented along the directions of principal moment capacity). On this basis he reproduced and supplemented Johansen's yield line solutions, showing that many were in fact exact, in the sense that coinciding lower bounds exist.

At the same time yield line theory was receiving wider attention in the world. Johansen's pioneering paper [8] had already been published in German in 1932, and after the war the thesis [9] was first translated into Portuguese (for the Brazilian market). The English translation - sponsored by the C \& C A - appeared in 1962, followed by the catalogue of solutions (Yield Line Formulae [11]) a decade later. Nielsen's 1964 thesis [10] was published in English from the start.

In the 1960s yield line theory was the subject of considerable interest in the UK, as evidenced by a flurry of papers and monographs, including a special publication issued by Magazine of Concrete Research [12], including contributions by L L Jones, K O Kemp, C T Morley, M P Nielsen and R H Wood. A particular subject under debate was whether Johansen's yield criterion (see Section 4 below) was compatible with limit analysis. Jones \& Wood went so far as to state in 1967 [13] that 'such a criterion is useless within the strict framework of limit analysis, which must develop its own idealised criteria of yield. Until yield-line theory and limit analysis employ the same criterion of yield, they must go their own separate ways', c.f. also Wood [14]. The controversy was not helped by the attitude of Prof Johansen himself, who refused to acknowledge that his yield line theory had anything to do with 
limit analysis, which he derisively dismissed as pure mathematical formalism. He had a point in the sense that yield line theory is certainly more than just an upper bound calculation, cleverly applied it gives a wider insight into the behaviour of the slab, including the distribution of reactions.

In 1970, however, Braestrup [15] showed that not only is the Johansen criterion consistent with limit analysis, as evidenced by the work of Nielsen, it is indeed the only possible yield condition for a slab that allows complete solutions (coinciding upper and lower bounds) to be derived by yield line analysis. The message was brought home in 1974 when Fox [16] determined the exact yield load for the clamped, isotropic slab under uniform loading. This fairly simple case had long defied attempts of solution, and this fact had been cited as evidence of the incompatibility of yield line theory and limit analysis. Fox's analysis of the square, clamped slab is not a proper yield line solution, because it includes finite regions with a negative Gaussian curvature. However, yield line analysis provides a close estimate, and by successively refining the yield line pattern, the exact solution can be approximated to any desired degree, which is the point. Slabs or plates obeying other yield conditions (eg Tresca or v. Mises) can also be analysed by yield lines, but except for trivial cases the resulting upper bound will never approach the exact solution, however detailed the yield line pattern.

It is interesting to note that, unbeknownst to most participants in the debate 40 years ago, limit analysis and yield line theory had for many years peacefully coexisted in the Soviet Union. Gvozdev [17] had already formulated the limit analysis theorems in 1938, but his work was not widely known in the West until it was translated to English in 1960. Whereas the Prager school of plasticity was mainly concerned with metallic structures, Gvozdev's point of departure was reinforced concrete, in particular slabs, and his version of yield line analysis was published in 1939 [18].

\section{NODAL FORCES}

One controversial and little understood aspect of Johansen's yield line theory is the concept of nodal forces (in Danish: 'knudekræfter'). Limit analysis provides an upper bound for the yield load (i.e. one number only), using the work equation for the entire slab. Yield line analysis, on the other hand, considers the equilibrium of the individual slab parts, simplifying the calculations by projecting loads and moments in yield lines onto the axis about which the slab part rotates at failure. This provides information about the direction in which the yield line pattern should be modified to improve the solution. Johansen found, however, that in order to arrive at the correct answer it is necessary to introduce certain self-equilibrating forces on the adjoining slab parts at points where yield lines intersect each other or a free boundary, and he derived the corresponding nodal force formulae for isotropic and orthotropic slabs. The physical reality of the nodal forces is bound up with the Kirchhoff boundary condition, converting the twisting moment along a discontinuity to a pair of forces at the ends. In 1965 Møllmann showed that the nodal force values derived by Johansen are exactly those loads needed to maintain equilibrium of the individual slab parts when the yield line pattern is optimised.

It follows from this insight that a nodal force formula corresponds to a degree of freedom for the yield line pattern. Thus if the considered point of intersection is pre-determined (e.g. as a re-entrant corner on a free boundary, a point load on the slab, or a point of symmetry) then there is no geometric parameter to optimise and the nodal force is not given by the corresponding formula, but by equilibrium of the adjoining slab parts, the geometries of which are now determined. This was never fully explained by Johansen, giving rise to much confusion [19].

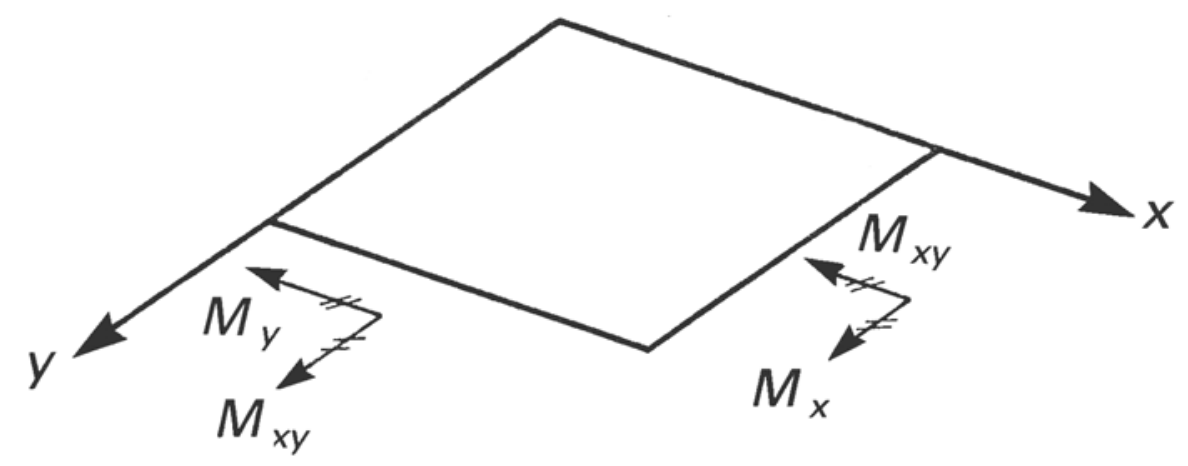

Fig. 1 Definition of slab bending and twisting moments. 


\section{YIELD CONDITION FOR ARBITRARLY REINFORCED SLABS}

The state of stress in a slab is described by the moments $M_{x}, M_{y}$ and $M_{x y}$ measured per unit length in a Cartesian coordinate system, as in Fig. 1 . Note that $\mathrm{M}_{\mathrm{xy}}$ is a component of the symmetric moment tensor, i.e. positive if the twisting moment vector on a section perpendicular to the $\mathrm{x}$-axis is directed into the section.

The rate of internal work per unit length of a yield line is:

$$
W_{\mathrm{l}}=\mathrm{M}_{\mathrm{n}} \theta_{\mathrm{n}}
$$

where $\theta_{n}$ is the jump in slope and $M_{n}$ is the bending moment in the section defined by the normal $n$, directed at the angle $\varphi$ to the x-axis, cf Fig. 2. The yield line is termed positive or negative according to the sign of $\theta_{n}$.

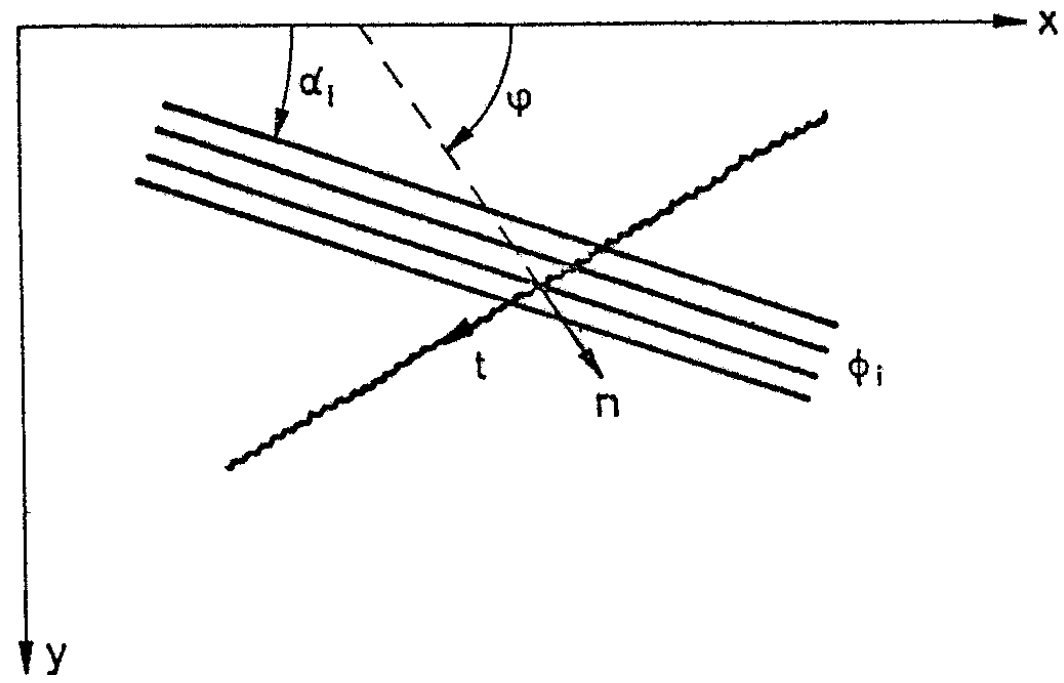

Fig. 2 Yield line crossing a band of reinforcement.

A yield condition for the slab is found by assuming that the strength of a section is described by the bending moment capacity only, leading to the yield condition:

$$
-M_{F}^{\prime}(\varphi) \leq M_{n} \leq M_{F}(\varphi)
$$

This is called the 'normal moment criterion', Kemp [20], and the one-dimensional 'yield surface' is visualized in Fig. 3.

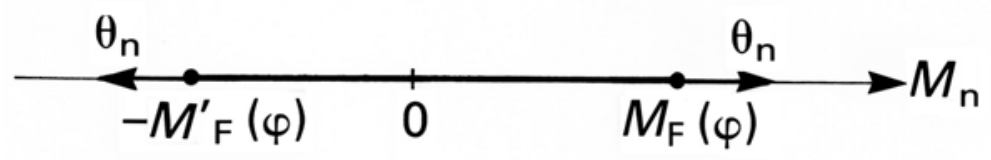

Fig. 3 Normal moment criterion.

For a non-isotropic slab the positive yield moment $M_{F}$ and the negative yield moment $M_{F}^{\prime}$ are functions of the angle $\varphi$ defining the direction of the yield line. These functions are called 'polar diagrams' and in yield line analysis they are assumed to take the form:

$$
\begin{aligned}
& M_{F}(\varphi)=\Sigma M_{i} \cos ^{2}\left(\varphi-\alpha_{i}\right) \\
& M_{F}^{\prime}(\varphi)=\Sigma M_{i}^{\prime} \cos ^{2}\left(\varphi-\alpha_{i}\right)
\end{aligned}
$$


The summation extends over all bands of reinforcement crossing the yield line, defined by the angles $\alpha_{i}$ and reinforcement ratio $\Phi_{i}$, see Fig. 2. The corresponding yield moments $M_{i}$ and $M_{i}^{\prime}$ for the individual reinforcement bands may be calculated in accordance with the preferred building code as functions of the reinforcement ratio and effective depth, using the appropriate stress block factors. The directions $\alpha_{i}$ of positive (bottom) and negative (top) reinforcement may be different, but in that case the contribution of compressed reinforcement to the yield moment is neglected.

Equation (3) may be written:

$$
\begin{aligned}
M_{F}(\varphi)= & M_{F x} \cos ^{2} \varphi+M_{F y} \sin ^{2} \varphi+2 M_{F x y} \cos \varphi \sin \varphi, \\
\text { where } \quad M_{F x} & =\Sigma M_{i} \cos ^{2} \alpha_{i} \\
M_{F y} & =\Sigma M_{i} \sin ^{2} \alpha_{i} \\
M_{F x y} & =\Sigma M_{i} \cos \alpha_{i} \sin \alpha_{i}
\end{aligned}
$$

Analogous expressions can be derived for negative yield lines, described by Equation (4).

For an orthotropic slab with the coordinate axes oriented along the reinforcement directions, Equation (5) reduces to $M_{F}(\varphi)=M_{F x} \cos ^{2} \varphi+M_{F y} \sin ^{2} \varphi$, where $M_{F x}$ and $M_{F y}$ are the yield moments of the $x$-, respectively $y$-band reinforcement. This is Johansen's 'stepped' yield criterion, so called because he imagined the yield lines to be composed of small sections perpendicular to the two reinforcement directions. For an isotropic slab $M_{F x}=M_{F y}=M_{F}$, and the criterion reduces to $M_{F}(\varphi)=$ $\mathrm{M}_{\mathrm{F}}$.

In terms of the stress resultants defined in Fig. 1 the bending moment in an arbitrary section defined by the normal $\mathrm{n}$ is given by the transformation formula:

$$
M_{n}=M_{x} \cos ^{2} \varphi+M_{y} \sin ^{2} \varphi+2 M_{x y} \cos \varphi \sin \varphi,
$$

For each value of the parameter $\varphi$ the normal moment criterion $M_{n}=M_{F}(\varphi)$ represents a plane in the 3-dimensional $M_{x}, M_{y}, M_{x y}$ - space, which is a supporting plane to the yield surface. The yield surface itself is determined as the envelope of the family of planes as $\varphi$ varies, and the equation of the surface is found by eliminating $\varphi$ between Equation (6) - with $M_{n}=M_{F}(\varphi)$ inserted from Equation (5) - and the equation obtained by differentiating with respect to $\varphi$. Braestrup [15]. A similar argument applies to the criterion for negative yield, and the result is the yield condition:

$$
\begin{array}{ll}
\theta_{n}>0: & -\left(M_{x}-M_{F x}\right)\left(M_{y}-M_{F y}\right)+\left(M_{x y}-M_{F x y}\right)^{2} \leq 0 \\
\theta_{n}<0: & -\left(M_{x}+M_{F x}^{\prime}\right)\left(M_{y}+M_{F y}^{\prime}\right)+\left(M_{x y}+M_{F x y}^{\prime}\right)^{2} \leq 0
\end{array}
$$

Equations (7) represent a bi-conical yield surface, shown in Fig. 4. Moment states on the two conical surfaces correspond to either positive, or negative yield lines, respectively, or to regions with zero Gaussian curvature. The two vertices correspond to the intersection of either positive, or negative, yield lines, or to regions with positive Gaussian curvature. Finally, the elliptical intersection of the two cones corresponds to the intersection of positive with negative yield lines, or to regions with negative Gaussian curvature. Gvozdev [21] already in 1966 determined the yield condition represented by Fig. 4, but in parametric form as the family of hyperbolas obtained by intersection of the surface by planes corresponding to constant $\mathrm{M}_{\mathrm{xy}}$, c.f. also Kemp [22].

A possible yield surface for the slab is any convex surface that is inscribed in the bi-conical surface in such a way that all generatrices (i.e. supporting planes) are touched. However, for general yield line solutions to be possible the yield surface must include the vertices (to allow intersecting yield lines of the same sign) and the elliptical intersection (to allow intersecting yield lines of opposite sign). Therefore Equations (7) represent the only yield surface that makes it possible to develop complete yield line solutions. 


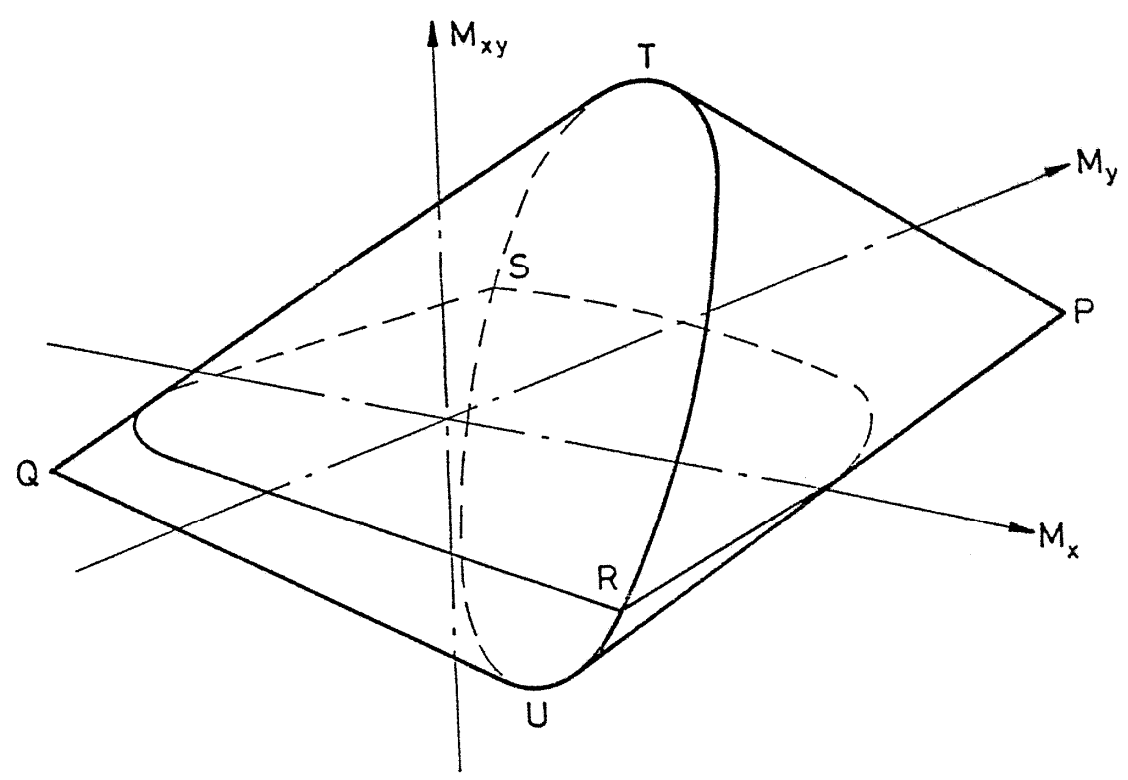

Fig. 4 Yield surface for arbitrarily reinforced slab.

The vertices of the two cones are at the points $\left(M_{x}, M_{y}, M_{x y}\right)=\left(M_{F x}, M_{F y}, M_{F x y}\right)$ and $\left(M_{x}, M_{y}, M_{x y}\right)=$ $\left(-\mathrm{M}_{\mathrm{Fx}}^{\prime},-\mathrm{M}_{\mathrm{Fy}},-\mathrm{M}_{\mathrm{Fxy}}^{\prime}\right)$. As seen from Equation (5) these coordinates may be regarded as components of two symmetrical resistance tensors, cf Gvozdev [21]. The yield condition (7) then simply states that the determinant of the difference between the moment tensor and the resistance tensor is nonnegative.

It is always possible to choose the coordinate system is such a way that either $\mathrm{M}_{\mathrm{Fxy}}=0$ or $\mathrm{M}_{\mathrm{Fxy}}^{\prime}=$ 0 . If the corresponding coordinate directions coincide, the yield surface of Fig. 4 will have both vertices in the plane $M_{x y}=0$, and it was derived by Nielsen [10]. The typical case is orthotropic reinforcement with coordinate axes along the reinforcement directions. If in particular $M_{F x}=M_{F y}$ and $M_{F x}^{\prime}=M_{F y}^{\prime}$ (isotropic reinforcement) the yield surface may be represented as a square yield locus in the plane of principal moments, see Prager [4].

\section{CONCLUSIONS}

These days it would be difficult to locate a serious researcher who doubts that yield line theory is fully compatible with limit analysis, but it is not widely appreciated that the Johansen criterion is in fact the only yield condition for the slab that allows coinciding upper and lower bounds to be derived by yield line analysis.

The yield condition is generally known as the square yield locus for isotropic slabs or Nielsen's biconical surface for orthotropic slabs. In fact, the general Equations (7), represented by Fig 4, is the most convenient formulation for checking the permissibility of a given stress state, being valid for any reinforcement arrangement. For orthotropic slabs the use of Equations (7) obviates a coordinate transformation, and the principal directions of the top and bottom reinforcement need not coincide.

\section{REFERENCES}

[1] Hodge, P.G, and Prager W., "A Variational Principle for Plastic Materials with Strainhardening", Journal of Mathematics and Physics, 27(1), 1948, pp 1-10.

[2] Drucker, D.C. "Some Implications of Work Hardening and Ideal Plasticity", Quarterly of Applied Mathematics, 7, 1950, pp 411-418.

[3] Drucker, D.C., Prager, W. and Greenberg. H.J., "Extended Limit Analysis Theorems for Continuous Media", Quarterly of Applied Mathematics, 9, 1952, pp 381-389.

[4] Prager, W. "The General Theory of Limit Design", Proc $8^{\text {th }}$ International Congress of Theoretical and Applied Mechanics, II, 1955, pp 65-72.

[5] Hill, R., The Mathematical Theory of Plasticity, Clarendon, Oxford, 1950, 356 pp.

[6] Coulomb, C.A. "Essai sur une application des régles de maximis \& minimis á quelques problèmes statique, relatifs a l'architecture", Mémoires de Mathématique \& de Physique 
présentés a l'Académie Royale des Sciences, 7, 1776, pp 343-382. (English translation: "Note on an Application of the Rules of Maximum and Minimum to some Statical Problems, Relevant to Architecture", In Heyman, J., Coulomb's Memoir on Statics: An Essay in the History of Civil Engineering, Cambridge University Press, 1972, 212 pp.)

[7] Ingerslev, A., "Om en elementær beregningsmetode af krydsarmerede plader (On a Simple Analysis of Two-Way Slabs)", Ingeniøren, 30, 69, 1921, pp 507-515. (See also: "The Strength of Rectangular Slabs", Struct. Eng., 1, 1, 1923, pp 3-14.)

[8] Johansen, K.W., "Beregning af krydsarmerede jernbetonpladers brudmoment", Bygningsstatiske Meddelelser, 3, 1, 1931, pp 1-18 (German version: "Bruchmomente der Kreuzweise bewehrten Platten", Mem. Int. Ass. Bridge Struct. Eng., 1, 1932, pp 277-296.)

[9] Johansen, K.W., Brudlinieteorier, Gjellerup, Copenhagen, 1943, 189 pp. (English translation: Yield-Line Theory, Cement and Concrete Association, London, 1962).

[10] Nielsen, M.P., Limit Analysis of Reinforced Concrete Slabs, Acta Polytechnica Scandinavica, Civil Engineering and Building Construction Series, 26, 1964, 167 pp.

[11] Johansen, K.W., Yield-Line Formulae for Slabs, Cement and Concrete Association, London, 1972, 106 pp.

[12] Recent Developments in Yield-Line Theory, MCR Special Publication, Cement and Concrete Association, London, 1965.

[13] Jones, L.L. and Wood, R. H., Yield-Line Analysis for Slabs, Thames \& Hudson and Chatto \& Windus, London, 1967, $405 \mathrm{pp}$.

[14] Wood, R. H., "A Partial Failure of Limit Analysis of Slabs", Magazine of Concrete Research, 21, 67, 1969, pp 79-80 (Discussion, 22, 21, 1970, pp 112-113.)

[15] Braestrup, M.W., "Yield Line Theory and Limit Analysis of Plates and Slabs", Magazine of Concrete Research, 22, 71, 1970, pp 99-106.

[16] Fox, E.N., "Limit Analysis for Plates: The Exact Solution for a Clamped Square Plate of Isotropic Homogeneous Material Obeying the Square Yield Criterion and Loaded by Uniformly Pressure", Philosophical Transactions of the Royal Society, London, 277, 1265, 1974, pp 121155.

[17] Gvozdev, A.A., "Opredelenie velichiny razrushayushchei nagruzki dlya statischeski neopredelimykh sistem, preterpevayushchikh plasticheskie deformatsii", Svornik trudov konferentsii po plasticheskim deformatsiyam, Akademia Nauk SSSR, Moscow-Leningrad, 1938, pp 19-30. (English translation: "The Determination of the Value of the Collapse Load for Statically Indeterminate Systems Undergoing Plastic Deformation", International Journal of Mechanical Sciences, 1, 1960, pp 322-333.)

[18] Gvozdev, A.A, "Obosnovanie $\S 33$ norm proektirovaniya zhelezobetonnykh konstruktsii (Comments to $\S 33$ of the design standard for reinforced concrete structures)", Stroitelnaya Promyshlenmnost, 17, 3, 1939, pp 51-58.

[19] Braestrup, M.W., "Discussion of K. Cederwall and A. Li: The Application of the Nodal Force Concept in Yield-Line Analysis", Nordic Concrete Research, 9, 1990, pp 213-214.

[20] Kemp, K.O., "A Lower Bound Solution to the Collapse of an Orthotropically Reinforced Slab on Simple Supports", Magazine of Concrete Research, 14, 41, 1962, pp 79-84.

[21] Gvozdev, A.A, "Sur le calcul par la métode des lignes de rupture des dalles en béton pour disposition quelconque des armatures", CEB Bulletin 56, 1966, pp 152-155.

[22] Kemp, K.O., "The Yield Criterion for Orthotropically Reinforced Concrete Slabs", International Journal of Mechanical Sciences, 7, 1965, pp 737-746. 